\title{
Values as predictors of anticipated socio-cultural adaptation among potential migrants from Russia to Finland
}

\section{Yijälä, Anu}

2012

Yijälä , A , Lönnqvist , J-E , Jasinskaja-Lahti , I \& Verkasalo , M 2012 , ' Values as predictors of anticipated socio-cultural adaptation among potential migrants from Russia to Finland ', Journal of Community and Applied Social Psychology , vol. 22 , no. 2 , pp. 95-100 . https://doi.org/10.1002/casp.110

http://hdl.handle.net/10138/234353

https://doi.org/10.1002/casp.1104

acceptedVersion

Downloaded from Helda, University of Helsinki institutional repository.

This is an electronic reprint of the original article.

This reprint may differ from the original in pagination and typographic detail.

Please cite the original version. 
Running Head: VALUES AND ANTICIPATED ADAPTATION

Accepted author manuscript.

Yijälä, A., Lönnqvist, J. E., Jasinskaja-Lahti, I., \& Verkasalo, M. (2012).

Values as predictors of anticipated socio-cultural adaptation among potential migrants from Russia to Finland. Journal of Community \& Applied Social Psychology, 22(2), 95-110.

Values as predictors of anticipated socio-cultural adaptation among potential migrants from Russia to Finland

Anu Yijäläa ${ }^{\mathrm{a}}$ Jan-Erik Lönnqvist ${ }^{\mathrm{b}}$, Inga Jasinskaja-Lahtia ${ }^{\mathrm{a}}$ Markku Verkasalo ${ }^{\mathrm{b}}$

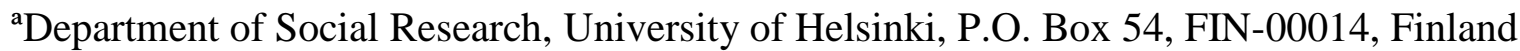

${ }^{\mathrm{b}}$ Institute of Behavioral Science, University of Helsinki, P.O. Box 9, FIN-00014, Finland

Author Note:

This research was supported by the Academy of Finland Research Grants 123297 and 127641. We would like to thank Tamara Kinunen (St. Petersburg State University, Russia), Sirkku Varjonen (Department of Social Research, University of Helsinki, Finland), and Michail Vinokurov (State University of Petrozavodsk, Russia) for helping with the data collection, as well as Elina Leinonen (Department of Social Research, University of Helsinki, Finland) for her help in data coding.

Correspondence concerning this article should be addressed to Anu Yijälä, Department of Social Research, University of Helsinki, P.O. Box 54, FIN-00014 University of Helsinki. E-mail: anu.yijala@helsinki.fi; tel. +358 9191 24187; fax. +358 919124835. 


\section{Abstract}

This study examined the role of value patterns of potential migrants from Russia to Finland $(N=229)$ in predicting expectations of post-migration socio-cultural adaptation. Furthermore, the fit between migrants' personal values and the values they expect to encounter in the new home country (i.e., perceived value congruence) was hypothesized to predict anticipated socio-cultural adaptation (ASCA). The study took into account perceived cultural distance variables as well as socio-demographic controls traditionally related to adaptation outcomes among migrants. According to the results, familiarity with the host country (i.e., the number of Finnish friends/relatives in Finland), the openness to change value, and perceived value congruence significantly predicted potential migrants' ASCA. When using four sub-scales (interpersonal relations, cognitive understanding, impersonal perils and bureaucracy) of the ASCA-scale, a more complex picture emerged. The results suggest that future work should include values, particularly perceived value congruence, in the analysis of the cultural fit hypothesis, as well as find better means of supporting immigrant adjustment starting at the pre-migration stage.

Keywords: Pre-migration acculturation, anticipated socio-cultural adaptation, potential migrants' personal values, perceived values of the hosts, perceived value congruence 
Values as predictors of anticipated socio-cultural adaptation among potential migrants from

$$
\text { Russia to Finland }
$$

\section{Socio-cultural adaptation and the role of expectations}

Voluntary migrants often make adjustments to their lives in anticipation of a migration by imagining or simulating the new social environment before entering it and by forming expectations of, for example, how they will be expected to behave (Black, Gregersen, Mendenhall, 1992). Both positive and accurate expectations have been shown to be connected to better post-migration adaptation outcomes (e.g., Black, 1992; Black \& Gregersen, 1990; Martin, Bradford, \& Rohrlich, 1995; Stroh, Gregersen, \& Black, 1998), including successful socio-cultural adaptation (Searle \& Ward, 1990; Tartakovsky, 2007) (i.e., the extent to which an individual manages his/her life in a new environment; Ward \& al., 2001). To our knowledge, there are only a few studies (Jasinskaja-Lahti \& Yijälä, in press; Yijälä, Jasinskaja-Lahti, Likki, \& Stein, in press) on how these expectations are formed in the pre-migration stage. This reflects a larger gap in current acculturation research, particularly the lack of understanding of the complexity and dynamics of the preacculturation process as experienced by potential migrants (also referred as self-initiated, self-designated, and future migrants) (Jasinskaja-Lahti \& Yijälä, in press). This study aims to identify specific pre-migration factors that influence the formation of migrants' expectations about socio-cultural adaptation in the country of immigration. We argue that it is the personal values (Schwartz, 1992) of potential migrants and their congruency with the values attributed to the members of the receiving society that are essential to understanding anticipated sociocultural adaptation. This study focuses on potential ethnic migrants from Russia to Finland, who represent Ingrian Finns - descendants of Finnish settlers in $17^{\text {th }}$ century Ingria 
(nowadays part of Russia). Many Ingrian Finns (around 25,000) remigrated to Finland after the collapse of the former Soviet Union. At the moment there are still, however, around 30,000 Ingrian Finns remaining in Russia.

\section{The model of factors predicting anticipated socio-cultural adaptation}

\section{Cultural distance between the society of origin and the receiving society}

Cultural distance is a concept used to define how culturally similar or different a person thinks his or her home country is compared with the new country of residence (see Babiker, Cox, \& Miller, 1980). Traditionally, several kinds of measures of perceived cultural distance, such as cultural similarity (Piontkowski, Florack, Hoelker, \& Obdrzálek, 2000; Rohmann, Florack, \& Piontkowski, 2006) and culture novelty (e.g., Black \& Stephens, 1989; Torbiörn, 1982) have been used. This line of research has shown that the smaller the perceived cultural distance, the easier it is for the immigrant to psychologically and socio-culturally adapt to a new country (e.g., Searle \& Ward, 1990; Suanet \& van de Vijver, 2009; for results in the Finnish context, see Gregersen \& Stroh, 1997).

Not all studies, however, have confirmed the connection between cultural distance and adaptation (see e.g., Holopainen \& Björkman, 2005; Tung, 1998), and some researchers have criticized previous studies for exaggerating this connection (e.g., Gaertner \& Dovidio, 2000). For example, Jun and Gentry (2005) have concluded that it was not the cultural similarity between home and host countries, but rather the expatriates' ability to fit into the host culture that resulted in successful adaptation. This observation is in accordance with socalled cultural fit hypothesis, which asserts that it is not the personality per se which predicts adaptation, but rather the fit between the acculturating individual and the new culture (Ward \& Chang, 1997). When assessed through personality traits (e.g., Ward \& Chang, 1997) and 
cultural orientations (e.g., Jun \& Gentry, 2005), empirical examinations of the congruence/discrepancy between the individual's characteristics and the mean tendency of the host society have supported the cultural fit hypothesis (for contradicting results see, e.g., Ward, Leong, \& Low, 2004; Ward \& Searle, 2001). As regards to the previous research on the cultural fit hypothesis utilizing values, it has often been assumed migrants hold values identical to those of their home cultures, and, thus, value differences have been approached in terms of cultural fit as determined by group-level differences in country-level dimensions, such as individualism and collectivism (Suanet \& van de Vijver, 2009). In this study, we test the cultural fit hypothesis in relation to anticipated socio-cultural adaptation and propose that, along with perceived cultural distance, perceived value congruence should be taken into account.

\section{Personal values}

We argue, first, against the assumption that individual migrants have values similar to a nationally representative sample of the population. For example, according to Tartakovsky and Schwartz (2001), "people may be motivated to emigrate in order to pursue their whole set of life goals, that is, their values," and therefore potential migrants may differ from their average co-nationals. Previous research has also shown that immigrants tend to affiliate with a destination society holding values similar to their own. Donà and Berry (1994) found that those immigrants who had more individualistic values preferred more individualistic cultures, whereas those immigrants who displayed more collectivistic values tended to stay away from cultures with more individualistic values. Moreover, in their study on potential migrants from Russia, Tartakovsky and Schwartz (2001) showed that personal values predicted their preferred destination of emigration. These findings indicate that personal values and 
discrepancies between values of them and those ascribed to the country of immigration may affect migrants' cultural affiliations.

Second, we argue that the values of potential migrants may not only influence their chosen destination and post-migration adaptation, but they may also affect their anticipated socio-cultural adaptation to the new society. In this study, values were approached in the framework created by Schwartz and colleagues (e.g., Schwartz \& Bilsky, 1987; Schwartz, 1992). In their approach, values can be defined as trans-situational goals that serve as guiding principles in the life of a person or group. According to this model, at the level of the individual, people in most cultures distinguish between at least ten basic values: benevolence, tradition, conformity, security, power, achievement, hedonism, stimulation, self-direction, and universalism. These are thought to represent the universal value types that form a continuum of related motivations giving rise to the circular structure shown in Figure 1 (Schwartz, 1992).

The ten basic values can be further categorized into four higher-order value priorities that form a two-dimensional taxonomy of personal values. On the first axis, selftranscendence values, universalism and benevolence (i.e., values emphasizing acceptance of others as equals and concern for their well-being), are opposed to self-enhancement values, achievement and power (i.e., values emphasizing own relative success and control over others). The second axis opposes conservation values, conformity, tradition and security (i.e., values emphasizing self-restriction, preservation of traditional practices, and protection of stability), to openness to change values, self-direction and stimulation (i.e., values emphasizing own independent thought and action that favour change). Hedonism valuelocated between the openness to change and the self-enhancement poles-does not clearly fit to any of these four value priorities (Schwartz, 1992.) 


\section{INSERT FIGURE 1 AROUND HERE}

In the present study, we investigated three ways in which the framework provided by Schwartz' values theory could facilitate our understanding of anticipated socio-cultural adaptation prior to migration. We suggest that personal values will predict the expectations potential migrants have regarding their post-migration socio-cultural adaptation. Openness to change values are likely to be the most relevant basic value in this respect; a potential migrant who emphasizes his/her own independent thought and action that favor change (Schwartz, 1992) may see the move to a new country as an exciting, positive challenge and, as a result, expect to adapt smoothly adaptation to that country. On the contrary, as customs, practices, and conventions are most likely to be different in the host and home countries, adherence to conservation values could be associated with expecting more difficulties in adapting to the new way of life. We also argue that not only personal values, but also beliefs about the value climate of the host society will predict anticipated socio-cultural adaptation. If a typical member of the host country is expected to be helpful, friendly, broadminded, and just (Schwartz, 1992) - i.e., as adhering to self-transcendence values — then immigrants may expect fewer difficulties in adjusting. On the contrary, perceiving hosts to emphasize selfenhancement values, which refer to adherence to achievement and power (Schwartz, 1992), could be expected to predict more anticipated adaptation difficulties.

Cultural estrangement has recently been conceptualized as discrepancies between personal values priorities and perceived societal values (Bernard, Gebauer, Maio, 2006). Moreover, not sharing the common frame of values of one's society has been linked to alienation (Parsons, 1951), poor adaptation (Stromberg \& Boehnke, 2001; van Vianen, De 
Pater, Kristof-Brown, \& Johnson, 2004) and poor well-being (Sagiv \& Schwartz, 2000) in different contexts. If value congruence thus promotes positive adaptation outcomes, then immigrants who expect people in the host country to be similar to themselves in terms of values may expect fewer difficulties in adaptation. Therefore, we argue that it is the fit between personal values and the values one ascribe to the country of immigration that predicts anticipated socio-cultural adaptation.

\section{Hypotheses}

The aim of this study is to investigate factors predicting potential migrants' anticipated sociocultural adaptation to a new country. Based on the previous research reviewed above, we expect familiarity with the country of immigration (i.e., previous visits and prior contacts) to be positively related to anticipated socio-cultural adaptation, whereas the degree of perceived cultural distance (i.e., perceived dissimilarity and cultural novelty) to be negatively related to anticipated socio-cultural adaptation (H1). In addition, we hypothesize that potential migrants' personal values will predict anticipated socio-cultural adaptation: the more a potential migrant emphasizes openness to change values (as opposed to conservation values) the less she/he will expect difficulties in adaptation (H2). Further, potential migrants' perceived values of a typical Finn are expected to predict anticipated socio-cultural adaptation: the more a potential migrant believes the hosts to emphasize self-transcendence values (as opposed to self-enhancement values), the less she/he will expect difficulties in adaptation (H3). Finally, we assume that the congruence between the values of the potential migrants and how they perceive the values of typical host country representatives predicts anticipated socio-cultural adaptation: the greater the congruence, the fewer anticipated adaptation difficulties (H4). These hypotheses are tested while controlling for the effects of 
age and gender on anticipated socio-cultural adaptation, as these factors have usually been controlled for in post-migration studies on socio-cultural adaptation.

\section{Method}

\section{Participants and Data collection}

This study is a part of a larger research project investigating the migration of Ingrian Finns and their families to Finland (Intervening at the pre-migration stage: Providing tools for promoting integration and adaptation throughout the migration process; INPRES). The sample of this study consisted of 229 potential migrants of Finnish ethnic background (with at least one ethnically Finnish parent) (females 67.5\%; $n=154$ ) living in the Republic of Karelia or the Leningrad area. Their mean age was 44.4 years (ranging between 19 and 85 years, $S D=15.1)$. Most $(82.8 \%)$ of them had attended higher education. They had applied for repatriate status approximately $12.2(S D=3.1)$ years ago. The vast majority $(90.8 \%)$ had visited Finland before, and $63.2 \%$ had friends and/or relatives already living in Finland. The main data $(n=195)$ were collected at the Finnish language courses of the immigration training program organized by Finnish authorities in Russia during spring 2008. In addition, the questionnaire was mailed to those potential migrants who had already passed the language test and were waiting to be assigned a particular place of residence in Finland $(n=$ 34). The questionnaire was back-translated into Russian from the original English version by two bilingual official translators at the Language centre of the University of Helsinki and it was pilot tested among potential migrants in St. Petersburg.

\section{Measures}

All measures used in this study were developed for the INPRES project or modified from existing scales, as described below. 
Anticipated socio-cultural adaptation (ASCA). Participants' expectations of sociocultural difficulties they were to face after migration were measured by modifying the sociocultural adaptation scale (SCAS; Ward \& Kennedy, 1999) to fit the pre-migration context. Of the 29 items of the original scale, 26 were included (see Table 1). Participants rated the anticipated difficulty of different aspects of life in Finland on five point scale with higher scores reflecting greater social difficulty (i.e., poorer anticipated socio-cultural adaptation). A composed score of ASCA items was used (Cronbach alpha .94).

The SCAS has previously been used unidimensionally (e.g., Ward, Okura, Kennedy, \& Kojima, 1998) or bi-dimensionally (cognitive and behavioural aspects of socio-cultural adaptation; e.g., Swagler \& Jome, 2005) in the post-migration context only (for use among short-term sojourners before assignments, see Ward \& Kennedy, 1996). Therefore it was necessary to re-investigate its structure in the context of this study. Factor analysis (maximum likelihood, varimax rotation) revealed four meaningful factors with eigenvalues greater than one: Interpersonal relations (e.g., communicating with Finns, making friends), Cognitive understanding (e.g., understanding Finnish value system, understanding the Finnish world view), Impersonal perils (e.g., finding food that you enjoy, going shopping), and Dealing with bureaucracy (e.g., dealing with the authorities, following rules and regulations) (see Table 1). These factors explained $59.3 \%$ of the total variance. For the purpose of the following analyses, factor scores for each factor were computed. The internal consistency reliabilities of the subscales were estimated with the General Reliability Coefficient (GRC; Tarkkonen \& Vehkalahti, 2005). The GRC is particularly well suited for the assessment of factor scores' reliabilities, as it does not make the same assumptions about the equal variances and correlations of items as Cronbach alpha coefficient. The GRC for interpersonal relations was $.96, .80$ for cognitive understanding, .73 for impersonal perils, and .66 for 
bureaucracy.

\section{INSERT TABLE 1 AROUND HERE}

Personal values. Values were measured with the 21-item European Social Survey (ESS; Jowell et al., 2003) version of the Portrait Values Questionnaire (PVQ; Schwartz et al., 2001), based on descriptions of different people, whose goals, aspirations and wishes are characterized in two sentences. For example, "It is important to him/her to show his/her abilities. S/he wants people to admire what s/he does," measures the achievement value. The PVQ was administered in self-rating format $(1=$ not like me at all to $5=$ like $m e)$. In order to control for individual variation in scale use, each item was divided by the mean of all items before the ten basic values were computed as averages of the relevant items (Schwartz, 1992), and further categorized into four higher-order value priorities. The Alpha for the openness to change was $.66, .75$ for conservation, .78 for self-enhancement, and .71 for selftranscendence.

Perceived values of a typical Finn. Participants were asked to indicate their perceptions of the values of a typical Finn with the same PVQ that was used to measure the migrants' own values, but this time the participants reported what they believed a typical Finn would answer. The Alpha for perceived openness to change was $.53, .79$ for conservation, .72 for self-enhancement, and .73 for self-transcendence.

Perceived value congruence. The value profiles, based on the ten basic values presented in Figure 1, were used to compute an index of perceived value similarity between participants' personal values and their perceptions of values held by a typical Finn. As the elevation of the values profile is thought to reflect response bias (Schwartz, 1992), only the shape of the profile matters in the assessment of the similarity between two values profiles, 
making the Pearson's correlation coefficient between two profiles an appropriate statistic. Before correlating the profiles within participants, they were standardized between participants, thus controlling for those elements common to all ratings (Cronbach, 1955). Fisher's $r$ to $z$ was used before the correlation coefficients were entered into any analyses. High scores on the resulting index of value congruence reflect high perceived similarity.

Familiarity with Finland. Familiarity with Finland prior to migration was assessed by asking participants if they had ever visited Finland, and, if so, the number of visits. The variable Previous visits to Finland was coded into two categories $(0=$ no previous visits, $1=$ previously visited). In addition, two single-item questions were used to assess the size of participants' social networks in Finland. The participants indicated the size of their networks of Finnish friends and Finnish relatives using a 5 -point scale $(0=$ none to $5=10$ or more $)$. The answers were then combined into a single score (Number of Finnish friends/relatives in Finland), representing their overall Finnish social networks in Finland.

Cultural novelty. Using a modified version of the Culture Novelty measure introduced by Torbiörn (1982; see also Black \& Stephens, 1989), participants were asked to rate how similar $(1=$ very similar to $5=$ very different $)$ Russia and Finland were in four cultural aspects. "Work culture" was added to the original items (everyday customs, general living conditions, and -costs). Due to weak correlations with the other items an original item regarding climate was left out (Cronbach alpha .65).

Perceived similarity. Using a modified Perceived Cultural Similarity scale (Piontkowski et al., 2000; Rohmann et al., 2006), participants were asked to rate on five-point scale $(1=$ very similar to $5=$ very dissimilar $)$ how different or similar they perceived Russia and Finland to be in five different domains (general similarity, culture, mentality, family life, and gender roles) (Cronbach alpha .54). 


\section{Data analysis}

Hierarchical regression analyses were performed to study the role of values and perceived value congruence in predicting the level of anticipated socio-cultural adaptation among potential migrants. The aim was to explore whether values could increase the explanatory power of the model after the effect of cultural familiarity and distance variable is taken into account. Five separate analyses were performed for ASCA, as well as for each of its four subscales. Before conducting the regression analyses, the relationships between the dependent and independent variables used in the analyses were investigated using Pearson correlation coefficients. The data were analyzed using PASW Statistics 17.

\section{Results}

Using independent samples t-tests, we tested whether there are differences between the participants who had already passed the language test and those still participating in the premigration training in terms of their socio-demographic characteristics (age and gender), familiarity with Finland (previous visits to Finland and Finnish friends and/or relatives in Finland), and the level of anticipated socio-cultural adaptation. No statistically significant differences were found, except age and previous visits to Finland, with those participants who had already passed the language test being older and having visited Finland more often than those from the language courses. The impact of these variables on the dependent variables was taken into account in the following analyses as well as the differences between these two subgroups were considered when interpreting the results of this study. Descriptive statistics of the variables used are presented in Table 2. Pearson correlations between the independent variables and ASCA's subscales are presented in Table 3. 
INSERT TABLES 2-3 ABOUT HERE

We conducted a series of hierarchical regression analyses for ASCA and its four subscales, with variables entered into the models in five steps. In the first block, age and gender were entered as control variables. The familiarity variables (i.e., previous visits to Finland and number of Finnish friends/relatives) and variables measuring cultural distance (i.e., cultural novelty and perceived similarity) were included in the second block. In the case of self-rated values of potential migrants (third block) vis-à-vis their perceived values of a typical Finn (fourth block), the four higher-order value priorities were used ${ }^{1}$. In the final block, perceived value congruence was added. Table 4 shows the results of the final $\left(5^{\text {th }}\right)$ step of the factor analysis predicting ASCA, as well as those conducted separately for its four subscales. Finally, Table 5 displays the increase in variance explained by each block of variables entered, indicating that it can contribute to the prediction of ASCA once previously entered variables are controlled for.

As regards the testing of the hypotheses (see Table 4), our first hypothesis was only partly supported. Neither of the so-called cultural distance variables predicted ASCA. However, providing some support for the first hypothesis, the more Finnish friends and/or relatives the potential migrants had in Finland, the less difficulty they anticipated after migration $(\beta=-.18, p=.016)$. In regard to our hypotheses $\mathrm{H} 2-\mathrm{H} 4$, the openness to change value $(\beta=-.25, p=.016)$ and perceived value congruence $(\beta=-.16, p=.037)$ contributed to the prediction of variance in ASCA. Contrary to our third hypothesis, participants' perceived values of a typical Finn did not predict their ASCA. As can be seen from Table 5, the addition of personal values in the third step $\left(\mathrm{R}^{2}\right.$ Change $\left.=.06, p=.03\right)$ and of the value congruence in the fifth step $\left(\mathrm{R}^{2}\right.$ Change $\left.=.02, p=.037\right)$ of the analysis significantly increased 
the explained variance of the model.

\section{INSERT TABLE 4 AROUND HERE}

According to the results obtained for the four separate dimensions of ASCA, the significant predictors of the interpersonal relations subscale were the number of Finnish friends and/or relatives in Finland $(\beta=-.21, p=.007)$ and openness to change $(\beta=-.22, p=$ .043) (see Table 4). Against the cultural fit hypothesis, cultural distance variables did not significantly affect interpersonal relations. Perceiving the typical Finn as adhering to the selftranscendence value was a significant predictor $(\beta=-.27, p=.007)$ of the second dimension of ASCA, cognitive understanding. The other significant predictor of cognitive understanding was perceived value congruence $(\beta=-.22, p=.006)$. Interestingly enough, neither cultural distance nor the familiarity variables predicted this dimension of ASCA. The third dimension of ASCA, impersonal perils had the highest number of significant predictors. Particularly, in their own steps, previous visits to Finland $(\beta=-.19, p=.018)$, cultural novelty $(\beta=.17, p=$ $.048)$, self-transcendence value $(\beta=-.21, p=.022)$, and perceived value congruence $(\beta=-$ $.17, p=.034)$ all significantly predicted potential migrants' anticipated socio-cultural adaptation in terms of impersonal perils. The final, fourth dimension of ASCA, bureaucracy, was not successfully predicted by any of the variables hypothesized. ${ }^{2}$

INSERT TABLE 5 AROUND HERE

\section{Discussion}


In line with our hypotheses, the results obtained for the general index of anticipated sociocultural adaptation showed that, along with cultural familiarity through having friends and/or relatives living in a country of future immigration, the values of the potential migrant, particularly openness to change value, and the value congruency between these and perceived values of a typical Finn predicted overall socio-cultural adaptation expectations. On the contrary, participants' perceived values of a typical Finn did not have any effect on these expectations.

The results obtained for different dimensions of anticipated socio-cultural adaptation supported this general pattern but also revealed some meaningful differences. Having established friends/family networks in Finland prior to migration and, subsequently, having more experiences of interacting with Finns was related to fewer anticipated adaptation difficulties, specifically in terms of the quality of interpersonal relations (i.e., competence when communicating with Finns). In addition, those scoring high in the openness to change value perceived it easier to engage in new communicative situations with Finns after migration. One possible explanation for this may stem from the pre-migration stage per se. When the actual migration is still ahead, it seems reasonable to assume that those migrants who adhere to the openness to change value expect fewer difficulties related to future life changes or do not perceive these changes to be as demanding as compared to those migrants who adhere to, for example, conservation value.

As regards the cognitive understanding and impersonal perils dimensions of anticipated socio-cultural adaptation, the more participants perceived Finns as adhering to the self-transcendence value — which assumes mutual caring as well as basic similarities among people and cultures (Schwartz, 1992) — the less they expected difficulties in understanding the Finnish world view and value system after migration. Interestingly, those adhering to the 
self-transcendence value expected less difficulty in managing everyday practicalities after migration. In contrast, those potential migrants whose personal values differed largely from those attributed to a typical Finn expected more difficulties, particularly in the cognitive understanding of various aspects deeply rooted into the cultural inheritance of a new country of residence (e.g., understanding the Finnish world view and value system), but also in managing every-day impersonal tasks. Thus, it seems that in addition to psychological wellbeing (e.g., Sagiv \& Schwartz, 2000), congruence between the potential migrants' personal values and their perceptions of values prevailing in the future home society may also affect a more behavioral side of adaptation, namely socio-cultural adaptation. These results support our assumption that, in addition to perceptions of country-level differences, deeper psychological processes take place when forming expectations of social life in a new country. The results also support the notion of van Vianen et al. (2004) regarding the importance of value congruence for predicting different types of adjustment.

The results of this study did not only show how values relate to different dimensions of anticipated socio-cultural adaptation, but also produced new information related to the cultural fit hypothesis. Eventually, cultural distance (i.e., culture novelty) predicted only a single subscale, impersonal perils, composed of items related to expected difficulties in the most basic everyday activities in a new society. One possible reason for this may be related to the measurement of cultural distance. Typically, cultural distance has been assessed by identifying easily visible dissimilarities between home and host countries, such as general living conditions, everyday customs, and climate. According to van Vianen and colleagues (2004; see also Harrison, Price, \& Bell, 1998), these dissimilarities refer to so-called surfacelevel cultural differences, as opposed to deeper cultural differences, such as dissimilarities in basic values and attitudes. Based on the results of this study, value congruence was clearly 
more important predictor of anticipated socio-cultural adaptation than cultural distance variables. Also in their recent longitudinal study on expatriate adaptation, van Vianen et al. (2004; see also McNulty, 2009) found that while surface level cultural differences (measured using Cultural Novelty Scale, Black \& Stephens, 1989) were related only to expatriates’ general adjustment to new environment and living conditions, perceiving differences between expatriates and host nationals in terms of deep-level cultural values (i.e., self-transcendence value) was connected to both increased interaction and work adjustment. Hence, in future studies it may be worth of including also the measurement of deep cultural differences to account for differences in immigrant pre- and/or post-migration adjustment.

A possible reason for the absence of effects of cultural fit in some previous studies on values (e.g., Ward \& Searle, 1991) and the presence of effects in the present study may be the different technique to compute value congruence. In the present study, value congruence was based on the difference between participants' personal values and the perceived values of a typical Finn, whereas previous studies have often used statistical formulas to compute differences in the profiles of the participants and their host countries, which implies that attributes discovered on a cultural level are directly_ and often mistakenly (see Bond, 2002)—related to an individual level. Basing on person- environment fit theory (Edwards, Caplan, \& van Harrison, 1998), which assumes that perceived environment is a more proximal predictor of attitudes than actual environment, we believe that even though the perceptions of potential migrants may not accurately reflect values commonly represented in the Finnish society, they are, nevertheless, more proximal predictors of perceived differences in values than if the congruence was extracted from the country-level estimates.

We note the special nature of the population studied here (i.e., ethnic, voluntary migrants) leads to certain limitations when generalizing the results to other groups of 
potential migrants. For example, ethnic background may have had an effect on the migrants' personal values being closer to those values they perceived as typical for the Finns, increasing value congruence. In our study, especially those potential migrants who had already passed the language test seemed to have a better experience of Finland as compared to those who were still attending immigration training courses. However, controlling for these differences, the results clearly showed the importance of perceived value congruence when predicting anticipatory adaptation among potential migrants. Furthermore, one possible limitation of the study is that some of the scales used had relatively low values of internal consistency. Regarding the rather low reliability of perceived openness to change value, it must, however, be noted that McCrae, Kurtz, Yamagata and Terracciano (in press) have reviewed the psychometric shortcomings of Cronbach alpha, showing that it is unrelated to the validity of NEO PI-R scales. Moreover, considering the use of cross-sectional data, the relationships studied should be interpreted with caution. However, considering the extensive amount of research on the cultural fit hypothesis, we have strong reason to believe that it is the perceived fit between the immigrant and new surroundings that precedes adaptation and not vice versa.

Despite these limitations, the present research allows the following conclusions. First, in addition to traditional cultural distance variables, other variables also explain the formation of the socio-cultural adaptation expectations about the future home country. Second, Schwartz's values theory provides a meaningful framework to study the formation of these expectations. Third, studying perceived value congruence provides a new and fruitful framework for analyzing adaptation expectations of new cultural surroundings. Finally, focusing on the pre-migration stage offers the chance to shed light on how migrants' expectations are formed. 
As regards practical recommendations based on our study, the personal values of potential migrants and perceived value congruence must be taken into account to enhance anticipatory and subsequent adjustment to help immigration authorities and organizations to develop programs for recruiting migrants. Moreover, self-selected migrants should be provided with sufficient and realistic information about prevailing values in the future home country to prepare them for possible value incongruence. Evidently, however, more research is needed to better understand and predict the pre-migration conditions that lead to the most adaptive pre-acculturation profiles and provide a favorable basis for post-migration adaptation in different migration contexts, and to address the role of values and value congruence in the adaptation of voluntary migrants. 
Table 1. Factor Loadings for Exploratory Factor Analysis With Varimax Rotation of the Anticipated Socio-cultural Adaptation Scale

\begin{tabular}{|c|c|c|c|c|}
\hline $\begin{array}{l}\text { How much difficulty do you expect to } \\
\text { experience in Finland in each of these } \\
\text { areas? }\end{array}$ & $\begin{array}{l}\text { Inter- } \\
\text { personal } \\
\text { Relations }\end{array}$ & $\begin{array}{l}\text { Cognitive } \\
\text { Under- } \\
\text { standing }\end{array}$ & $\begin{array}{l}\text { Im- } \\
\text { personal } \\
\text { Perils }\end{array}$ & $\begin{array}{c}\text { Bureau- } \\
\text { cracy }\end{array}$ \\
\hline 1. Making friends & .61 & .33 & .04 & .12 \\
\hline 2. Finding food that you enjoy & .22 & .06 & .58 & .24 \\
\hline 3. Following rules and regulations & .16 & .16 & .50 & .44 \\
\hline 4. Dealing with the authorities & .22 & .26 & .24 & .74 \\
\hline 5. Taking a Finnish perspective on the culture & .17 & .41 & .29 & .42 \\
\hline 6. Using the transport system & .27 & .06 & .44 & .41 \\
\hline 7. Dealing with bureaucracy & .46 & .23 & .04 & .74 \\
\hline 8. Understanding the Finnish value system & .12 & .68 & .19 & .31 \\
\hline 9. Making yourself understood & .57 & .52 & .00 & .31 \\
\hline $\begin{array}{l}\text { 10. Seeing things from the Finnish point of } \\
\text { view }\end{array}$ & .30 & .47 & .14 & .15 \\
\hline 11. Going shopping & .16 & .14 & .57 & .32 \\
\hline 12. Understanding jokes and humor & .32 & .55 & .14 & .02 \\
\hline 13. Accomodation & .62 & .18 & .15 & .26 \\
\hline 14. Going to social gatherings & .40 & .31 & .28 & .25 \\
\hline 15. Communicating with Finns & .60 & .45 & .20 & .13 \\
\hline $\begin{array}{l}\text { 16. Understanding ethnic or cultural } \\
\text { differences }\end{array}$ & .46 & .50 & .27 & .18 \\
\hline 17. Dealing with unsatisfactory service & .20 & .23 & .17 & .14 \\
\hline 18. Relating to members of the opposite sex & .56 & .16 & .28 & .10 \\
\hline 19. Finding your way around & .67 & .13 & .36 & .18 \\
\hline 20. Understanding the Finnish political system & .53 & .29 & .30 & .28 \\
\hline 21. Talking about yourself with others & .66 & .25 & .29 & .23 \\
\hline 22. Dealing with the climate & .03 & .28 & .55 & -.03 \\
\hline 23. Understanding the Finnish world view & .34 & .63 & .32 & .12 \\
\hline 24. Family relationships & .21 & .33 & .59 & .04 \\
\hline 25. The pace of life & .34 & .24 & .64 & .07 \\
\hline $\begin{array}{l}\text { 26. Being able to see two sides of an inter- } \\
\text { cultural issue }\end{array}$ & .23 & .58 & .39 & .20 \\
\hline
\end{tabular}


Table 2. Descriptive Statistics of the Variables Used in the Study

\begin{tabular}{lcc}
\hline & $M(S D)$ & Items (scale) \\
\hline Socio-cultural adaptation & $1.98(.56)$ & $26(1-5)$ \\
Cultural Novelty & $4.07(.50)$ & $4(1-5)$ \\
Perceived Similarity & $3.61(.61)$ & $5(1-5)$ \\
Personal Values* & & \\
Openness to change & $0.93(.14)$ & $4(1-5)$ \\
Conservation & $1.12(.18)$ & $6(1-5)$ \\
Self-Enhancement & $0.77(.18)$ & $4(1-5)$ \\
Self-Transcendence & $1.18(.16)$ & $5(1-5)$ \\
Perceived values of a Typical Finn* & & \\
Openness to Change & $0.88(.12)$ & $4(1-5)$ \\
Conservation & $1.17(.13)$ & $6(1-5)$ \\
Self-Enhancement & $0.86(.15)$ & $4(1-5)$ \\
Self-Transcendence & $1.08(.13)$ & $5(1-5)$ \\
\hline *Centered values & &
\end{tabular}


Table 3. Correlations Between Independent Variables and Anticipated Socio-cultural Adaptation

\begin{tabular}{|c|c|c|c|c|c|}
\hline & $\begin{array}{c}\text { General } \\
\text { ASCA }\end{array}$ & $\begin{array}{c}\text { Inter- } \\
\text { personal } \\
\text { Relations }\end{array}$ & $\begin{array}{c}\text { Cognitive } \\
\text { Under- } \\
\text { standing }\end{array}$ & $\begin{array}{l}\text { Im- } \\
\text { personal } \\
\text { Perils }\end{array}$ & $\begin{array}{c}\text { Bureau- } \\
\text { cracy }\end{array}$ \\
\hline Age & $.15^{*}$ & $.22 * *$ & -.11 & $.19 * *$ & $.20 *$ \\
\hline Sex & $-.20 * *$ & $-.28 * *$ & -.09 & .01 & -.12 \\
\hline $\begin{array}{l}\text { Previous visits to } \\
\text { Finland }\end{array}$ & -.07 & .01 & -.01 & -.13 & .01 \\
\hline $\begin{array}{l}\text { Number of Finnish } \\
\text { Friends/ Relatives in } \\
\text { Finland }\end{array}$ & $-.15^{*}$ & $-.21 * *$ & $-.17 *$ & .08 & .03 \\
\hline Cultural Novelty & .02 & -.07 & -.02 & .10 & -.02 \\
\hline Perceived Similarity & -.08 & .03 & -.07 & -.07 & .02 \\
\hline Personal values & & & & & \\
\hline Openness to change & $-.23 * *$ & $-.34 * *$ & -.13 & -.10 & -.04 \\
\hline Conservation & $.20 * *$ & $.33 * *$ & -.06 & .10 & .07 \\
\hline Self-Enhancement & -.10 & $-.22 * *$ & $.15^{*}$ & -.03 & -.06 \\
\hline Self-Transcendence & .00 & $.23 * *$ & -.07 & -.13 & -.06 \\
\hline $\begin{array}{l}\text { Perceived values } \\
\text { of a typical Finn }\end{array}$ & & & & & \\
\hline Openness to change & -.01 & -.11 & -.02 & .07 & .02 \\
\hline Conservation & .11 & $.21 * *$ & .05 & -.10 & .12 \\
\hline Self-Enhancement & .08 & -.02 & .12 & .05 & .06 \\
\hline Self-Transcendence & $-.18 *$ & -.05 & $-.23 * *$ & -.05 & $-.19 *$ \\
\hline $\begin{array}{l}\text { Perceived Value } \\
\text { Congruence }\end{array}$ & $-.18 * *$ & $-.20 * *$ & $-.14 *$ & -.08 & .00 \\
\hline
\end{tabular}


Table 4. The Hierarchical Regression Analyses ( $5^{\text {th }}$ step) of Factors Predicting Anticipated Socio-cultural Adaptation ( $\left.N=172\right)$, and Four of Its Subscales Studied $(N=156)$

\begin{tabular}{|c|c|c|c|c|c|}
\hline & $\begin{array}{c}\text { General } \\
\text { ASCA } \\
(\beta)\end{array}$ & $\begin{array}{c}\text { Interpersonal } \\
\text { Relations } \\
(\boldsymbol{\beta})\end{array}$ & $\begin{array}{c}\text { Cognitive } \\
\text { Understanding } \\
(\beta)\end{array}$ & $\begin{array}{c}\text { Impersonal } \\
\text { Perils } \\
(\beta)\end{array}$ & $\begin{array}{c}\text { Bureaucracy } \\
(\boldsymbol{\beta})\end{array}$ \\
\hline Age & .07 & .04 & -.16 & $.21 *$ & $.23 *$ \\
\hline Sex & -.10 & -.13 & -.17 & .14 & -.07 \\
\hline Previous visits to Finland & -.12 & .01 & -.07 & $-.18 *$ & -.02 \\
\hline Finnish Friends/Relatives in Finland & -.14 & $-.16^{*}$ & -.15 & .07 & -.04 \\
\hline Culture Novelty & .05 & -.01 & .02 & .14 & .01 \\
\hline Perceived Similarity & -.11 & -.01 & -.09 & -.16 & .11 \\
\hline Personal: Openness to change & $-.26 * *$ & $-.24 *$ & -.18 & -.15 & -.12 \\
\hline Personal: Conservation & -.02 & -.01 & -.07 & .05 & -.15 \\
\hline Personal: Self-Enhancement & -.09 & -.10 & .11 & -.02 & -.13 \\
\hline Personal: Self-Transcendence & -.10 & .04 & .09 & $-.23 *$ & -.24 \\
\hline Perceived Openness to change & .15 & .10 & .13 & .08 & .01 \\
\hline Perceived Conservation & .15 & .13 & .08 & -.04 & .18 \\
\hline Perceived Self-Enhancement & .10 & .06 & .04 & -.05 & .08 \\
\hline Perceived Self-Transcendence & -.14 & -.07 & $-.30 * *$ & -.01 & -.13 \\
\hline \multirow[t]{3}{*}{ Perceived Value Congruence } & $-.16 *$ & -.11 & $-.22 * *$ & $-.17 *$ & .10 \\
\hline & $\mathrm{R}^{2} \quad .22 *$ & $\begin{array}{ll}\mathrm{R}^{2} & .21\end{array}$ & $\mathrm{R}^{2} \quad .22 * *$ & $\mathrm{R}^{2} \quad .20 *$ & $\mathrm{R}^{2} \quad .15$ \\
\hline & $\Delta \mathrm{R}^{2} \quad .02 *$ & $\Delta \mathrm{R}^{2} \quad .01$ & $\Delta \mathrm{R}^{2} \quad .04^{* *}$ & $\Delta \mathrm{R}^{2} \quad .03 *$ & $\Delta \mathrm{R}^{2} \quad .01$ \\
\hline
\end{tabular}

\footnotetext{
$* p<.05, * * p<.01$
}

Note: $\Delta \mathrm{R}^{2}=$ Change in the variances $\left(\mathrm{R}^{2}\right)$ of the fifth step of the analyses 
Table 5. Blockwise Increases in Variance Explained in Regression Models Predicting Anticipated Socio-cultural Adaptation With All the Variables Studied

\begin{tabular}{|c|c|c|c|c|c|}
\hline & $\begin{array}{c}\text { General } \\
\text { ASCA }\end{array}$ & $\begin{array}{c}\text { Inter- } \\
\text { personal } \\
\text { Relations }\end{array}$ & $\begin{array}{l}\text { Cognitive } \\
\text { Under- } \\
\text { standing }\end{array}$ & $\begin{array}{l}\text { Im- } \\
\text { personal } \\
\text { Perils }\end{array}$ & $\begin{array}{l}\text { Bureau- } \\
\text { cracy }\end{array}$ \\
\hline $\begin{array}{l}\text { Block 1.Age and } \\
\text { Gender }\end{array}$ & $.06 * *$ & $.08 * *$ & .03 & $.05^{*}$ & $.06 * *$ \\
\hline $\begin{array}{l}\text { Block 2. Familiarity } \\
\text { with Finland and } \\
\text { Cultural Distance }\end{array}$ & .05 & .05 & .03 & $.07 *$ & .02 \\
\hline $\begin{array}{l}\text { Block 3.Self-Rated } \\
\text { Values }\end{array}$ & $.06^{*}$ & .05 & .04 & .05 & .01 \\
\hline $\begin{array}{l}\text { Block 4. Perceived } \\
\text { Values of a typical } \\
\text { Finn }\end{array}$ & .04 & .02 & $.08^{*}$ & .01 & .04 \\
\hline $\begin{array}{l}\text { Block 5. Perceived } \\
\text { Value Congruence }\end{array}$ & $.02 *$ & .01 & $.04 * *$ & $.03 *$ & .01 \\
\hline
\end{tabular}




\section{References}

Babiker, I. E., Cox, J. L., \& Miller, P. M. (1980). The measurement of cultural distance and its relationship to medical consultations, symptomatology and examination performance of overseas students at Edinburgh University. Social Psychiatry and Psychiatric Epidemiology, 15(3), 119-116.

Bernard, M. M., Gebauer, J. E., \& Maio, G. R. (2006). Cultural estrangement: The role of personal and societal value discrepancies. Personality and Social Psychology Bulletin, $32(1), 78-92$.

Black, J. S. (1992). Coming home: The relationship of expatriate expectations with repatriation adjustment and job performance. Human Relations, 45(2), 177-192.

Black, J. S., \& Gregersen, H. B. (1990). Expectations, satisfaction, and intention to leave of American expatriate managers in Japan. International Journal of Intercultural Relations, 14(4), 485-506.

Black, J. S., Gregersen, H. B., \& Mendenhall, M. (1992). Toward a theoretical framework of repatriation adjustment. Journal of International Business Studies, 23(4), 737-760.

Black, J. S., \& Stephens, G. K. (1989). The influence of the spouse on American expatriate adjustment and intent to stay in Pacific Rim overseas assignments. Journal of Management, 15(4), 529-544.

Bond, M. H. (2002). Reclaiming the individual from Hofstede's ecological analysis—a 20year odyssey: Comment on Oyserman et al. (2002). Journal of Personality and Social Psychology, 128(1), 71-77.

Cole, N., \& McNulty, Y. (2009). Why do female expatriates 'fit-in' better than males? IAIR, 6th Biennial Conference, August 15-19, 2009. Honolulu, Hawai'i, USA. 
Cronbach, L. J. (1955). Process affecting scores on "understanding others" and "assumed similarity". Psychological Bulletin, 52, 177-193.

Donà, G., \& Berry, J. W. (1994). Acculturation attitudes and acculturative stress of Central American refugees. International Journal of Psychology, 29(1), 57-70.

Edwards, J. R., Caplan, R. D., \& Van Harrison, R. 1998. Person-environment fit theory. In C. L. Cooper (Ed.), Theories of organizational stress (pp. 28-67). Oxford: University Press.Gaertner, S., \& Dovidio, J. F. (2000). Reducing intergroup bias: The common ingroup identity model (1st ed.). Newark: Psychology Press.

Graves, T. D. (1967). Acculturation, access, and alcohol in a tri-ethnic community. American Anthropologist, 69(3/4), 306-321.

Gregersen, H. B., \& Stroh, L. K. (1997). Coming home to the arctic cold: Antecedents to Finnish expatriate and spouse repatriation adjustment. Personnel Psychology, 50(3), 635654.

Harrison, D. A., Price, K. H., \& Bell, M. P. (1998). Beyond relational demography: Time and the effects of surface- and deep-level diversity on work group cohesion. Academy of Management Journal, 41(1), 96-107.

Holopainen, J., \& Björkman, I. (2005). The personal characteristics of the successful expatriate: A critical review of the literature and an empirical investigation. Personnel Review, 34(1), 37-50.

Jasinskaja-Lahti, I., \& Yijälä, A. (in press). The model of pre-acculturative stress. A premigration study of potential migrants from Russia to Finland. International Journal of Intercultural Relations, DOI:10.1016/j.ijintrel.2010.11.003.

Jowell, R. \& the Central Co-ordinating Team. (2003). European social survey 2002/2003: Technical report. London: Centre for Comparative Social Surveys, City University 
(2003). The data archive: Norwegian Social Science Data Services (NSD).

Jun, S., \& Gentry, J. W. (2005). An exploratory investigation of the relative importance of cultural similarity and personal fit in the selection and performance of expatriates. Journal of World Business, 40(1), 1-8.

Kealey, D. J. (1989). A study of cross-cultural effectiveness: Theoretical issues, practical applications. International Journal of Intercultural Relations, 13(3), 387-428.

Martin, J. N., Bradford, L., \& Rohrlich, B. (1995). Comparing predeparture expectations and post-sojourn reports: A longitudinal study of U.S. students abroad. International Journal of Intercultural Relations, 19(1), 87-110.

McCrae, R. R., Kurtz, J. E., Yamagata, S., \& Terracciano, A. (in press). Internal consistency, retest reliability, and their implications for personality scale validity. To be published in Personality and Social Psychology Review.

Parsons, T. (1951). The social system. Glencoe, IL: Free Press.

Piontkowski, U., Florack, A., Hoelker, P., \& Obdrzálek, P. (2000). Predicting acculturation attitudes of dominant and non-dominant groups. International Journal of Intercultural Relations, 24(1), 1-26.

Rohmann, A., Florack, A., \& Piontkowski, U. (2006). The role of discordant acculturation attitudes in perceived threat: An analysis of host and immigrant attitudes in Germany. International Journal of Intercultural Relations, 30(6), 683-702.

Sagiv, L., \& Schwartz, S. H. (2000). Value priorities and subjective well-being: Direct relations and congruity effects. European Journal of Social Psychology, 30(2), 177-198.

Schwartz, S. H. (1992). Universals in the content and structure of values: Theoretical advances and empirical tests in 20 countries. In M. P. Zanna (Ed.), Advances in Experimental Social Psychology, vol. 25 (pp. 1-65). San Diego, CA: Academic Press. 
Schwartz, S. H., \& Bilsky, W. (1987). Toward A universal psychological structure of human values. Journal of Personality \& Social Psychology, 53(3), 550-562.

Schwartz, S. H., Melech, G., Lehmann, A., Burgess, S., Harris, M., \& Owens, V. (2001). Extending the cross-cultural validity of the theory of basic human values with a different method of measurement. Journal of Cross-Cultural Psychology, 32(5), 519-542.

Searle, W., \& Ward, C. (1990). The prediction of psychological and sociocultural adjustment during cross-cultural transitions. International Journal of Intercultural Relations, 14(4), $449-464$.

Stroh, L., Gregersen, H., \& Black, J. S. (1998). Closing the gap: Expectations versus reality among repatriates. Journal of World Business, 33(2), 111-124.

Suanet, I., \& van de Vijver, F.R. (2009). Perceived cultural distance and acculturation among exchange students in Russia. Journal of Community \& Applied Social Psychology, 19(3), 182-197.

Swagler, M. A., \& Jome, L. M. (2005). The effects of personality and acculturation on the adjustment of North American sojourners in Taiwan. Journal of Counseling Psychology, $52(4), 527-536$.

Tabachnick, B. G. \& Fidell, L. S. (2006). Using multivariate statistics (5 ${ }^{\text {th }}$ ed.). Boston: Allyn \& Bacon.

Tarkkonen, L., \& Vehkalahti, K. (2005). Measurement errors in multivariate measurement scales. Journal of Multivariate Analysis, 96, 172-189.

Tartakovsky, E. (2007). A longitudinal study of acculturative stress and homesickness: Highschool adolescents immigrating from Russia and Ukraine to Israel without parents. Social Psychiatry and Psychiatric Epidemiology, 42(6), 485-494.

Tartakovsky, E., \& Schwartz, S. H. (2001). Motivation for emigration, values, wellbeing, and 
identification among young Russian Jews. International Journal of Psychology, 36(2), 88-99.

Torbiörn, I. (1982). Living abroad: Personal adjustment and personnel policy in the overseas setting. New York: Wiley.

Triandis, H. C. (1995). Individualism and collectivism. Boulder, CO: Westview.

Tung, R. L. (1998). American expatriates abroad: From neophytes to cosmopolitans. Journal of World Business, 33(2), 125-144.

Van Vianen, A. E. M., De Pater, I. E., Kristof-Brown, A. L., \& Johnson, E. C. (2004). Fitting in: Surface- and deep-level cultural differences and expatriates' adjustment. Academy of Management Journal, 47(5), 697-709.

Ward, C. (2001). The A, B, Cs of acculturation. In D. Matsumoto (Ed.), The handbook of culture and psychology (pp. 411-445). New York: Oxford University Press.

Ward, C., Bochner, S., \& Furnham, A. (2001). The psychology of culture shock. Routledge: Hove.

Ward, C., \& Chang, W. C. (1997). 'Cultural fit': A new perspective on personality and sojourner adjustment. International Journal of Intercultural Relations, 21(4), 525-533.

Ward, C., \& Kennedy, A. (1999). The measurement of sociocultural adaptation. International Journal of Intercultural Relations, 23(4), 659-677.

Ward, C., Leong, C., \& Low, M. (2004). Personality and sojourner adjustment: An exploration of the Big Five and the cultural fit proposition. Journal of Cross-Cultural Psychology, 35(2), 137-151.

Ward, C., \& Searle, W. (1991). The impact of value discrepancies and cultural identity on psychological and sociocultural adjustment of sojourners. International Journal of Intercultural Relations, 15(2), 209-225. 
Yijälä, A., Jasinskaja-Lahti, I., Likki, T., \& Stein, D. (in press). Pre-migration adaptation of highly skilled self-initiated foreign employees: A case of an EU agency. To be published in The International Journal of Human Resources Management.

Yijälä, A., \& Jasinskaja-Lahti, I. (2010). Pre-migration acculturation attitudes among potential ethnic migrants from Russia to Finland. International Journal of Intercultural Relations, 34(4), 326-339. 


\section{Footnotes}

${ }^{1}$ The intercorrelations between the value priorities were $<.70$, indicating no obstacles for their use in the same analysis; see Tabachnick \& Fidell, 2006, p. 90.

${ }^{2}$ We also checked for possible interaction effects of 1. perceived value congruence and conservation (vs. openness to change) values, and 2. perceived cultural similarity and conservation (vs. openness to change) values on ASCA. No significant interaction effects were found. 
Figure captions

Figure 1. Schwartz's (1992) model of relations between basic and higher order values. 